\title{
Correction to: Histologic transformation of $t(11 ; 18)$-positive MALT lymphoma presented with aberrant T-cell marker expression
}

\author{
Naoki Tamura ${ }^{1} \cdot$ Hirona Maeda ${ }^{2} \cdot$ Momoko Nishikori $^{1} \cdot$ Haruyuki Fujita $^{1} \cdot$ Masakatsu Hishizawa ${ }^{1} \cdot$ Hironori Haga $^{2}$. \\ Akifumi Takaori-Kondo ${ }^{1}$
}

Published online: 28 June 2020

(C) Japanese Society of Hematology 2020

\section{Correction to: \\ International Journal of Hematology (2020) 111:724-732 \\ https://doi.org/10.1007/s12185-019-02810-y}

In the original publication of the article, the "Conflict of Interest" has been published incorrectly. The corrected version is given below.

Conflict of interest: M. Nishikori receives honoraria from Eisai and funding from Eisai and Sumitomo Dainippon Pharmaceutical. A. Takaori-Kondo receives honoraria from Celgene, Bristol-Myers Squibb, Novartis, MSD, Kyowa Kirin, Asteras, and funding from Celgene, Ono, COGNANO, Thyas, Bristol-Myers Squibb, and has research support from Ono, Takeda, Chugai, Eisai, Nippon Shinyaku,
Asteras, Kyowa Kirin, Otsuka, Pfizer, Popuri, Ohara, Sanofi, and Kim's Korean Ginseng. All other authors do not have any conflict of interest to declare.

Publisher's Note Springer Nature remains neutral with regard to jurisdictional claims in published maps and institutional affiliations.
The original article can be found online at https://doi.org/10.1007/ s12185-019-02810-y.

Momoko Nishikori

nishikor@kuhp.kyoto-u.ac.jp

1 Department of Haematology and Oncology, Graduate School of Medicine, Kyoto University, 54 Shogoin Kawahara-cho, Sakyo-ku, Kyoto 606-8507, Japan

2 Department of Diagnostic Pathology, Kyoto University Hospital, 54 Shogoin Kawahara-cho, Sakyo-ku, Kyoto 606-8507, Japan 